\title{
Editorial Note: Role of Hand-crafted and Learned Representations for Multimedia Applications
}

Multimedia tools and applications gratefully acknowledges the editorial work of the scholars listed below on the special issue entitled, "Role of Hand-crafted and Learned Representations for Multimedia Applications."

Of 22 papers submitted to this issue, 14 were eventually accepted after a stringent peerreview process.

\section{Prof. Sang-Soo Yeo (Corresponding Guest Editor)}

Mokwon University, Daejeon, South Korea

ssyeo2010@gmail.com

\section{Daqiang Zhang}

Tongji University, China

dqzhang@tongji.edu.cn

\section{Irfan Mehmood}

COMSATS Institute of Information Technology, Attock, Pakistan

irfanmehmood@live.com 